\title{
Natural history of the ventricular septal defect in tricuspid atresia and its surgical implications ${ }^{1}$
}

\section{P. SYAMASUNDAR RAO}

From the Department of Pediatrics, Section of Pediatric Cardiology Medical College of Georgia, Augusta, Georgia, U.S.A.

We have previously reported isolated cases of anatomical and functional closure of ventricular septal defects in tricuspid atresia. To study this phenomenon further, clinical, angiographic, and pathological findings in 20 consecutive cases of tricuspid atresia were reviewed. Sixteen cases were found to have normally related great arteries (type I) and 4 had transposition (type II). In 6 of these patients there was evidence of closure of a ventricular septal defect; in 3 this was complete and in the other 3, partial. Five of these ventricular septal defect closures occurred in type I patients and one among type II. Increasing cyanosis and polycythaemia and/or disappearance of a previously heard murmur were observed in all patients; these signs are more conspicuous in complete closure than in partial.

The incidence of closure of ventricular septal defect in tricuspid atresia is 38 per cent and approximates to the incidence of spontaneous closure of isolated ventricular septal defects. Progressive muscular 'encroachment' of the margins of ventricular septal defects with subsequent fibrosis and covering by endocardial proliferation is the most likely mechanism of closure in tricuspid atresia. The factors initiating the closure of ventricular septal defect remain unknown, but because of its occurrence in patients both with and without previous shunt operations, it is reasonable to assume that closure of ventricular septal defect in tricuspid atresia is not initiated or accelerated by these surgical shunts.

Recent developments in surgical technique permit total surgical correction of tricuspid atresia at least in a physiological sense, but these operations can be successfully performed only in older children (over 8 years). Thus, palliation is essential in younger patients until they reach the age for total correction. A BlalockTaussig shunt is recommended in preference to a Glenn anastomosis because the latter may leave the left pulmonary circuit without blood supply if the ventricular septal defect closes. In type II cases, a large and non-restrictive ventricular septal defect is essential for survival of the patient after the Fontan operation. For this reason, the size of the ventricular septal defect should be evaluated before and at the time of surgical correction. If the ventricular septal defect is small in a type II case, resection of the ventricular septum or a complete bypass of the ventricular septal defect and right ventricle is necessary at the time of the Fontan operation.

Spontaneous closure of isolated ventricular septal defects is well known (Azevedo et al., 1958; Evans et al., 1960; Nadas et al., 1961; Arcilla et al., 1963; Bloomfield, 1964; Hoffman and Rudolph, 1965). In simple ventricular septal defect this is clearly beneficial to the patient. In some complex cardiac lesions, however, an open ventricular septal defect is necessary to maintain adequate intracardiac shunting essential for survival of the patient; these

\footnotetext{
'Presented in part at the 25th Annual Scientific Session of the American College of Cardiology, New Orleans, La., U.S.A., 23-26 February 1976.

Received_for publication 7 June 1976
}

have been named 'physiologically advantageous ventricular septal defects' (Rao and Sissman, 1971; Rao et al., 1974). Spontaneous closure of defects of this type is rare but does occur. We have previously reported isolated cases of spontaneous anatomical and intermittent functional closure of the ventricular septal defects in tricuspid atresia (Rao and Sissman, 1971 ; Rao et al., 1974). To study this phenomenon further clinical, angiographic, and pathological findings in 20 consecutive cases of tricuspid atresia seen at the Medical College of Georgia were reviewed. The purpose of this paper is to report these observations to assess the incidence of ventricular 
septal defect closure in tricuspid atresia, to review the anatomical and physiological consequences of such closure, to discuss the mechanism of closure, and to comment on the therapeutic implications of closure of the ventricular septal defect in tricuspid atresia.

\section{Subjects, methods, and results}

The clinical, catheterisation and angiographic, and necropsy findings in all cases of tricuspid atresia seen at the Medical College of Georgia between 1966 and 1974 were reviewed. The commonly accepted criteria were used for diagnosis and inclusion in this study (Gasul et al., 1966; Keith et al., 1967; Diehl et al., 1968; Nadas and Fyler, 1972). Twenty consecutive cases seen over the 8-year period (1966 to 1974) form the basis of this study. The diagnosis of tricuspid atresia was made by catheterisation and angiography in 11 patients, by catheterisation, angiography, and necropsy in 8, and by clinical findings alone in 1 . Nine infants presented with symptoms during the first month of life, 8 between 1 month and 1 year, and the remaining 3 between the ages of 1 and 2 years. Their ages at the time of death or last clinical examination varied from 4 days to 16 years, with a mean age of 5 years and a median age of 7 months. The sex distribution was 1.5:1 male-to-female and is consistent with the slight preponderance of males reported for this lesion (Neill and Brink, 1955; Taussig et al., 1973; Dick et al., 1975). These cases were grouped according to the modified Keith classification (Edwards and Burchell, 1949; Keith et al., 1967). Sixteen cases were classified as type I and four as type II, and further subgrouping is shown in Table 1. The relative frequency of these types is similar to that in other series (Keith et al., 1967; Diehl et al., 1968; Nadas and Fyler, 1972). One case with normally related great arteries had a large ventricular septal defect and pulmonary atresia and cannot be classified with the currently available classifications (Keith et al., 1967; Diehl et al., 1968); it is suggested that cases of this variant should be classified as type ID. Additional cardiac

Table 1 Classification of tricuspid atresia patients seen at the medical college of Georgia (1966-74)

\begin{tabular}{lll}
\hline & Type I & Type II \\
\hline A & 4 & - \\
B & 9 & 2 \\
C & 2 & 2 \\
D & 1 & - \\
\hline
\end{tabular}

anomalies were present in 13 patients (Table 2); these are not dissimilar to those in other series except that the aortic arch anomalies reported in type II by Marcano et al. (1969) were not seen in any type II patient in this series.

Of 20 cases reviewed, 6 had clinical, angiographic, or pathological evidence for closure of ventricular septal defect. Three patients had complete closure and 3 partial. Each of these cases will be presented briefly.

\section{Case reports}

\section{CASE 1}

A 4-week-old female infant with cyanosis and a pansystolic murmur was found at cardiac catheterisation (Table 3) and selective cineangiography to have tricuspid atresia with normally related great arteries and a moderate-sized ventricular septal defect (Fig. 1). The haematocrit was 57 per cent. Re-examination at 6 weeks and 3 months of age showed increased cyanosis and polycythaemia (haematocrit 63\%). The previously heard pansystolic murmur was still present. The chest $x$-ray showed diminished pulmonary vascular markings compared with the earlier film. At 5 months of age a grade 2/6 ejection murmur was heard and at 6 months the murmur was only grade $1 / 6$. The haematocrit had risen to 71 per cent. An aortopulmonary shunt (Waterston) was performed, and the infant appeared to improve, but two days later had a cardiac arrest and died.

At necropsy, the diagnosis of tricuspid atresia without transposition was confirmed. A patent foramen ovale and an ostium primum atrial septal defect were present. There was an endothelialised recess in the left ventricular aspect of the ventricular septum (Fig. 2A): this appeared to end blindly, but with little force a probe could be passed through to the right ventricle; with a light source on the left

Table 2 Additional cardiac defects in 13 of the 20 cases of tricuspid atresia

\begin{tabular}{ll}
\hline Persistent ductus arteriosus & 5 \\
Persistent left superior vena cava & 4 \\
Right aortic arch & 2 \\
Hypoplastic ascending aorta & 1 \\
Coarctation of aorta & 1 \\
Subaortic stenosis & 1 \\
Absent left pulmonary artery & 1 \\
Total anomalous pulmonary venous connection & 1 \\
Obstructed patent foramen ovale & 1 \\
\hline Total & $17 \star$ \\
\hline
\end{tabular}


ventricular side, a ventricular septal defect opening into the right ventricular cavity was seen after removal of the probe (Fig. 2B). It is believed that the defect was in fact completely closed, but that the probe ruptured the thin endothelial membrane closing a small ventricular septal defect. There was no valvar or infundibular pulmonary stenosis. The ascending aorta-to-right pulmonary artery anastomosis was patent.
CASE 2

The second patient was first seen at the Medical College of Georgia at the age of 22 months because of cyanosis. A pansystolic murmur was recorded. Right atrial angiography suggested a diagnosis of tricuspid atresia with atrial and ventricular septal defects and without transposition. A Glenn procedure was performed and the cyanosis improved. He was first seen by our paediatric cardiology group at

Table 3 Cardiac catheterisation data

\begin{tabular}{|c|c|c|c|c|c|c|c|c|c|}
\hline & $S V C$ & $I V C$ & $R A$ & $P V$ & $L A$ & $L V$ & $A o$ & $P A$ & $R V$ \\
\hline $\begin{array}{l}\text { Case } 1-1 \text { month } \\
\text { Oxygen saturation (\%) } \\
\text { Pressure (mmHg) }\end{array}$ & $\underline{62}$ & - & 69 & - & 89 & $\begin{array}{l}92 \\
110 / 6\end{array}$ & - & - & - \\
\hline $\begin{array}{l}\text { Case } 2-12 \text { years } \\
\text { Oxygen saturation }(\%) \\
\text { Pressure }(\mathrm{mmHg})\end{array}$ & $\begin{array}{l}65 \\
\text { mean }=10\end{array}$ & - & $\begin{array}{l}70 \\
a=11 \\
v=7 \\
\text { mean }=6\end{array}$ & 一 & $\begin{array}{l}80 \\
a=10 \\
v=7 \\
\text { mean }=6\end{array}$ & $\begin{array}{l}84 \\
116 / 7\end{array}$ & - & $\begin{array}{l}\text { RPA 67* } \\
\text { mean }=10^{\star}\end{array}$ & - \\
\hline $\begin{array}{l}\text { Case } 3-3 \text { days } \\
\text { Oxygen saturation }(\%) \\
\text { Pressure }(\mathrm{mmHg})\end{array}$ & - & - & $\begin{array}{l}28 \\
a=15 \\
v=7 \\
\text { mean }=9 \\
84 \\
a=22 \\
v=16 \\
\text { mean }=14\end{array}$ & $\overline{-}$ & $\begin{array}{l}31 \\
a=11 \\
v=8 \\
\text { mean }=8 \\
82 \\
a=22 \\
v=18 \\
\text { mean }=14\end{array}$ & $\begin{array}{l}80 \\
100 / 10\end{array}$ & - & - & $\overline{-}$ \\
\hline $\begin{array}{l}\text { Case } 4-6 \text { weeks } \\
\text { Oxygen saturation (\%) } \\
\text { Pressure (mmHg) }\end{array}$ & - & - & $\begin{array}{l}51 \\
a=20 \\
v=7 \\
\text { mean }=8\end{array}$ & 99 & $\begin{array}{l}87 \\
a=12 \\
v=10 \\
\text { mean }=6\end{array}$ & $\begin{array}{l}88 \\
82 / 5\end{array}$ & $\begin{array}{l}87 \\
80 / 45 \\
\text { mean }=60\end{array}$ & - & - \\
\hline $\begin{array}{l}\text { Case } 4-4 \text { months } \\
\text { Oxygen saturation }(\%) \\
\text { Pressure (mmHg) }\end{array}$ & - & - & $\begin{array}{l}56 \\
a=14 \\
v=5 \\
\text { mean }=7\end{array}$ & - & $\begin{array}{l}80 \\
a=5 \\
v=7 \\
\text { mean }=4\end{array}$ & $\begin{array}{l}82 \\
83 / 3\end{array}$ & - & - & - \\
\hline \multicolumn{2}{|c|}{$\begin{array}{l}\text { Case 4-after balloon septostomy } \\
\text { Pressure (mmHg) }\end{array}$} & & $\begin{array}{l}a=10 \\
v=3 \\
\text { mean }=4\end{array}$ & & $\begin{array}{l}a=7 \\
v=8 \\
\text { mean }=2\end{array}$ & & & & \\
\hline $\begin{array}{l}\text { Case } 6-5 \text { years } \\
\text { Oxygen saturation }(\%) \\
\text { Pressure (mmHg) }\end{array}$ & $\underline{52}$ & - & $\begin{array}{l}54 \\
v=14 \\
a=12 \\
\text { mean }=12\end{array}$ & - & $\begin{array}{l}86 \\
a=11 \\
v=11 \\
\text { mean }=9\end{array}$ & $\begin{array}{l}85 \\
114 / 9\end{array}$ & - & - & - \\
\hline $\begin{array}{l}\text { Case } 6-14 \text { years } \\
\text { Oxygen saturation (\%) } \\
\text { Pressure (mmHg) }\end{array}$ & 68 & - & $\begin{array}{l}68 \\
a=12 \\
v=11 \\
\text { mean }=10\end{array}$ & 97 & $\begin{array}{l}84 \\
a=12 \\
v=11 \\
\text { mean }=10\end{array}$ & $\begin{array}{l}84 \\
140 / 10\end{array}$ & $\begin{array}{l}84 \\
140 / 80 \\
(100 / 80) t\end{array}$ & $\begin{array}{l}84 \\
28 / 14 \ddagger \\
120 / 20\end{array}$ & $\begin{array}{l}84 \\
140 / 15\end{array}$ \\
\hline
\end{tabular}


the age of 12 years because of moderate exercise intolerance, increased cyanosis, and headaches. $\mathrm{He}$ then had a single second sound and a grade $2 / 6$ ejection murmur at the left sternal border. Chest $x$-rays showed a normal sized heart and finely reticular pulmonary vascular markings. The electrocardiogram showed right atrial enlargement and left ventricular hypertrophy, with a mean frontal plane vector of $-60^{\circ}$ and a counterclockwise loop. His haematocrit was 75 per cent. Cardiac catheterisation (Table 3 ) and selective cineangiography confirmed the diagnosis of type I tricuspid atresia, and showed a patent Glenn shunt. Left ventricular angiography showed no ventricular septal defect. The left pulmonary circuit appeared to fill by enlarged collateral vessels and the right by the Glenn shunt. A left subclavian-pulmonary artery anastomosis (Blalock-Taussig) was performed without incident. He improved clinically and the haematocrit dropped to 54 per cent. A repeat catheterisation with angiography at 15 years again confirmed closure of the ventricular septal defect. Both the Glenn and Blalock-Taussig shunts were functioning. The patient is now awaiting a Fontan operation.

\section{CASE 3}

This male infant presented with cyanosis on the third day of life. Pertinent findings on examination included conspicuous cyanosis and a grade $2 / 6$ systolic murmur at the left lower sternal border. Chest $x$-rays showed minimal cardiomegaly and decreased pulmonary vascular markings. The electrocardiogram showed right atrial enlargement, a mean frontal plane vector of $-30^{\circ}$, and left ventricular hypertrophy. Cardiac catheterisation (Table 3) and cineangiography showed tricuspid atresia with normally related great arteries. Selective left ventricular angiography demonstrated a very small crescent-like right ventricle opacified via a small ventricular septal defect (Fig. $3 \mathrm{~A}$ ). There was very severe systemic arterial desaturation, and an emergency ascending aorta-to-right pulmonary artery (Waterston) anastomosis was performed. The infant improvea, but two weeks later developed congestive heart failure, which was controlled medically. He was re-examined at $1,3,6$, and 10 months of age, and had a continuous murmur of the aortopulmonary anastomosis. The ventricular septal defect murmur was no longer heard. Though the cardiac failure was controlled, there were persistent cardiomegaly and increased pulmonary vascular markings. A repeat cardiac catheterisation (Table 3) and angiography at 1 year of age showed tricuspid atresia, with a well-functioning aortopulmonary shunt (Fig. $3 \mathrm{C}$ ). On left ventricular angiograms in the posteroanterior and left anterior oblique projections there was no evidence of the ventricular
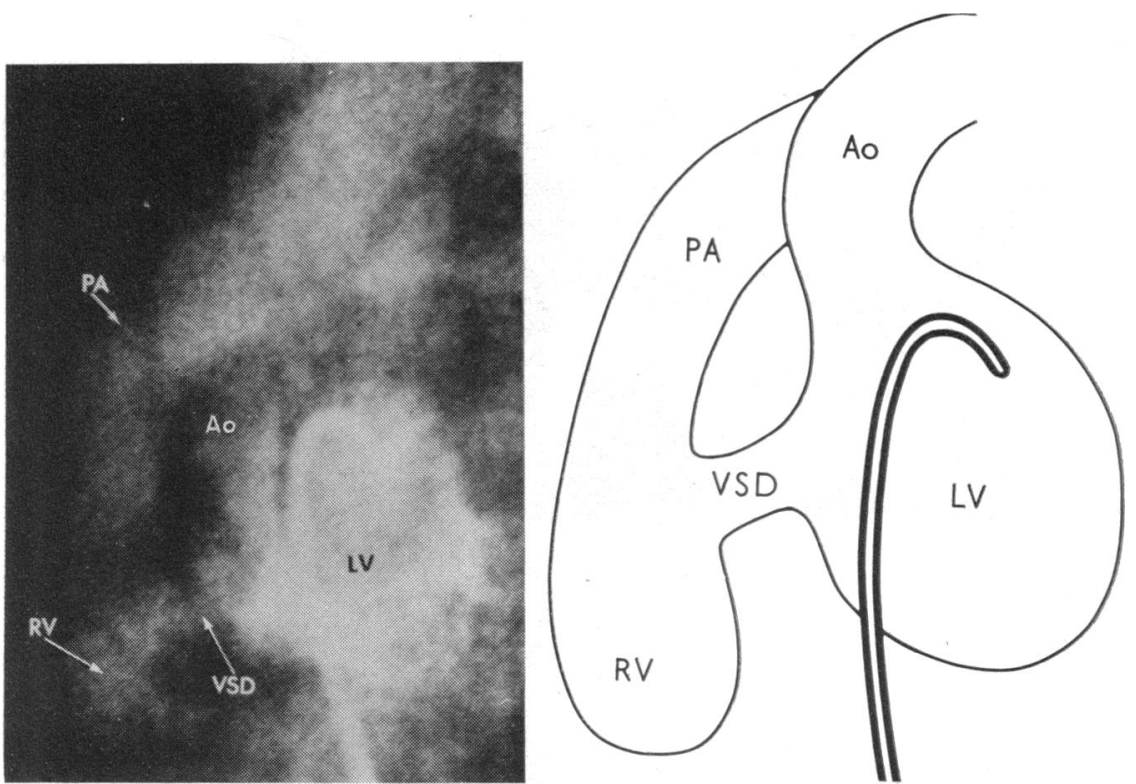

Fig. 1 Case 1. Selected frame from left ventricular cineangiogram (left anterior oblique view) showing opacification of the right ventricle $(R V)$ via ventricular septal defect (VSD). LV, left ventricle; $P A$, pulmonary artery. 
septal defect (Fig. $3 \mathrm{~B}$ and $\mathrm{C}$ ). Total anomalous pulmonary venous connection was seen then and on reinvestigation at the age of 4 years. This patient is now undergoing staged correction of the anomalous pulmonary venous return and tricuspid atresia.

\section{CASE 4}

This female infant presented with tachypnoea, intermittent cyanosis, and failure to thrive at 6 weeks of age. She then weighed less than at birth and was slightly cyanosed; there were signs of moderate congestive heart failure. The praecordium was hyperdynamic, and there was a grade $4 / 6$ pansystolic murmur with thrill at the left lower sternal border; the second heart sound was widely split with prominent pulmonary component and there was a loud apical third heart sound. The electrocardiogram showed a mean frontal plane vector of $-40^{\circ}$ and left ventricular hypertrophy. Chest $x$-ray showed considerable cardiomegaly and pulmonary plethora. The haematocrit was 52 per cent. The infant was admitted to hospital for treatment of heart failure. Cardiac catheterisation (Table 3) and selective cineangiography 3 days later showed type I tricuspid atresia, patent foramen ovale, and a large ventricular septal defect. Aortogram excluded

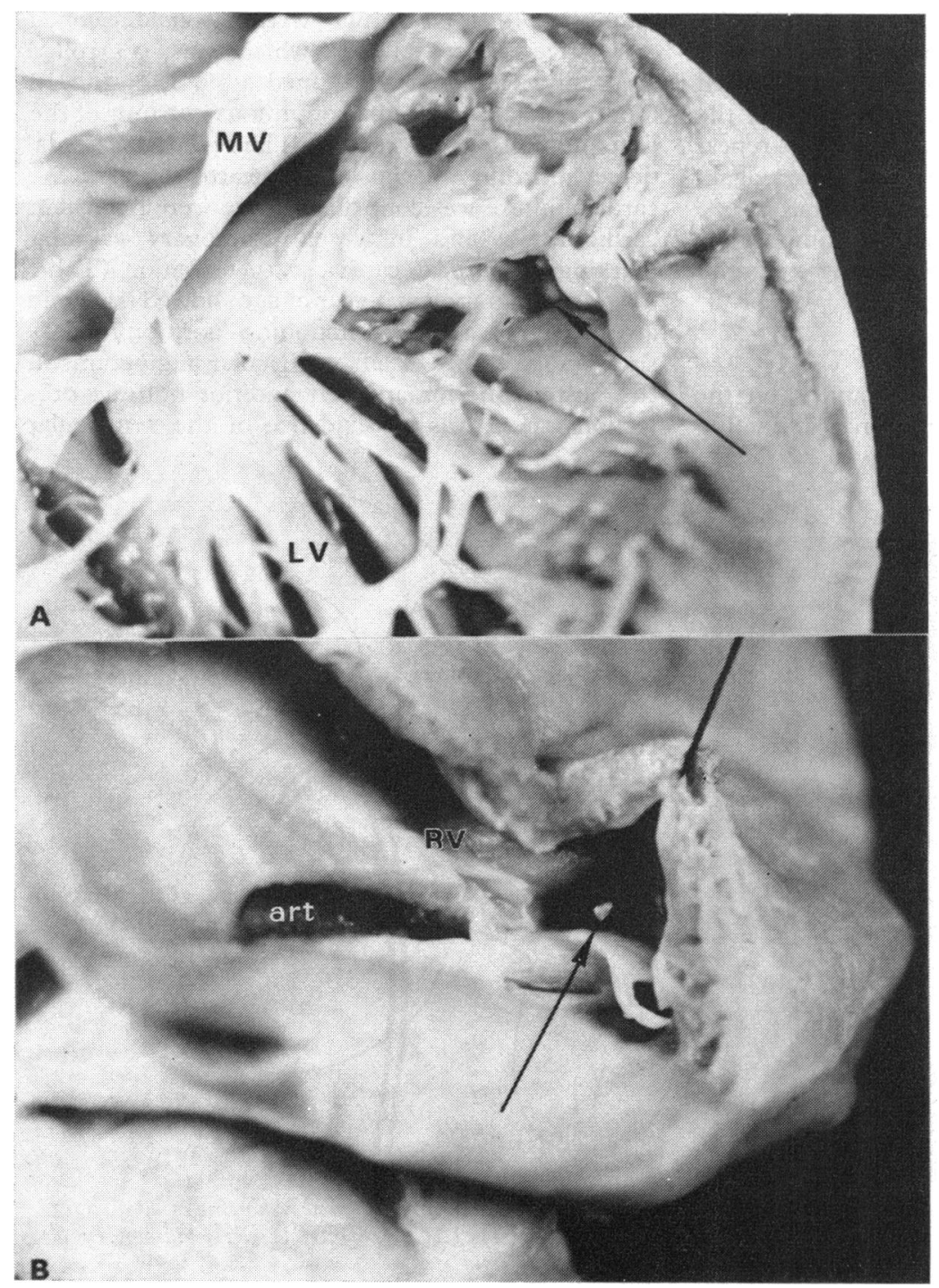

Fig. 2 Photographs of the heart of Case 1. (A) Left ventricular aspect of ventricular septum showing an endothelialised recess (arrow) which ended blindly. With little force a probe could be passed from this recess into the right ventricle. (B) Right ventricular aspect of septum after removal of probe (light source on left ventricular side). Ventricular septal defect (arrow) is seen to enter right ventricle $(R V)$. (See text for details.)

Art, artefact; $L V$, left ventricle; $M V$, mitral valve. 


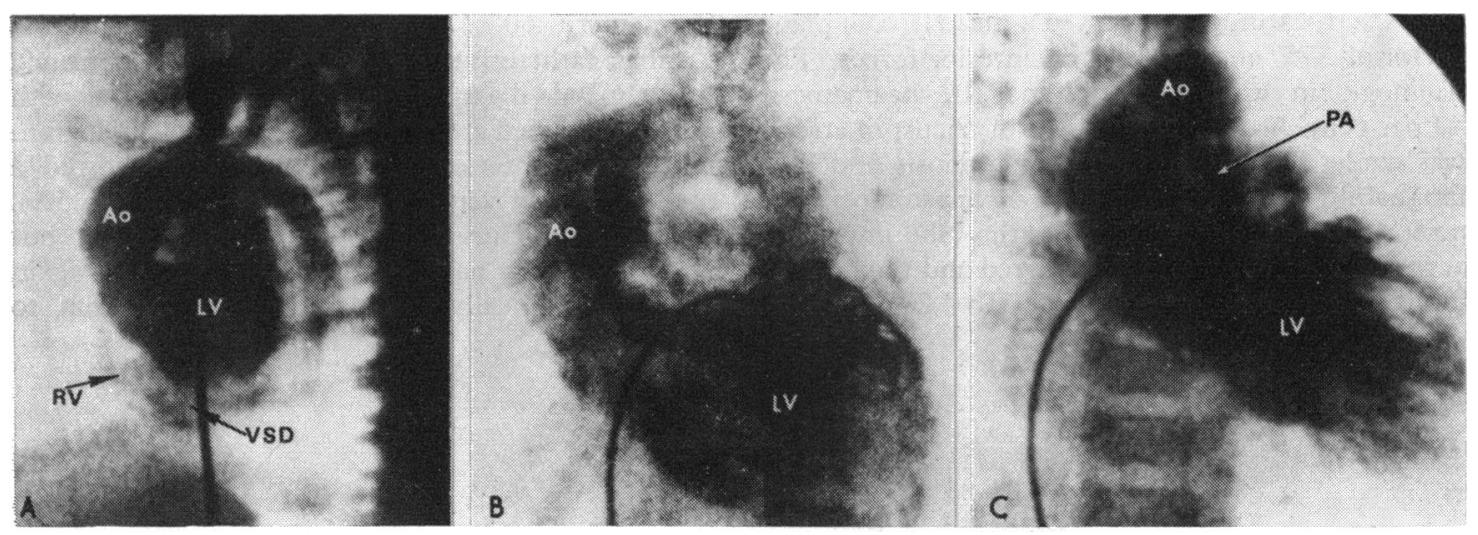

Fig. 3 Case 3. (A) Left ventricular cineangiogram at 3 days of age. Left anterior oblique projection. Simultaneous opacification of aorta (Ao) and small crescent shaped right ventricle (RV) via small ventricular septal defect (VSD). Left ventricular cineangiograms at 1 year of age in left anterior oblique $(B)$ and posteroanterior $(C)$ projections show no ventricular septal defect. Note opacification of pulmonary artery (PA) from aorta via Waterston anastomosis in $C$.

persistent ductus arteriosus. The calculated pulmonary-to-systemic flow ratio was greater than $2: 1$. After control of heart failure, the infant was discharged on treatment with oral digoxin and diuretics, but despite initial improvement, failed to gain weight. The physical findings two months later were unchanged except for prominent presystolic hepatic pulsation. A repeat catheterisation (Table 3) at that time showed a pressure gradient across the atrial septum suggesting obstruction at this site. This was relieved by balloon atrioseptostomy (Table 3) after which the presystolic hepatic pulsations disappeared; the infant improved and began to gain weight. She was examined regularly and at 12 months of age was considerably improved, with decrease in the heart size and pulmonary vascularity on $x$-ray suggesting a decrease in the size of the ventricular septal defect. The haemoglobin fell to about $15 \mathrm{~g} / \mathrm{dl}$ at 4 months of age and rose to about $18 \mathrm{~g} / \mathrm{dl}$ by 12 months of age concurrently with the decrease in pulmonary blood flow. The haemoglobin level remained unchanged over the next few months of life but began to rise steeply at 18 months of age. At 22 months because of high haemoglobin $(>20 \mathrm{~g} / \mathrm{dl})$, considerably decreased exercise tolerance, and constant hyperpnoea, a Blalock-Taussig anastomosis was performed. Repeat chest $x$-ray taken at 21 months showed further diminution in cardiac size and pulmonary blood flow. After the shunt operation the symptoms improved and the haemoglobin fell to $16 \mathrm{~g} / \mathrm{dl}$. Fig. 4 relates changes in haemoglobin level to the clinical course.
CASE 5

This female infant was seen at the age of 5 months because of cyanosis, and on examination had a grade $4 / 6$ pansystolic murmur at the left lower sternal border. The chest $x$-ray showed minimal cardiomegaly and decreased pulmonary vascularity.

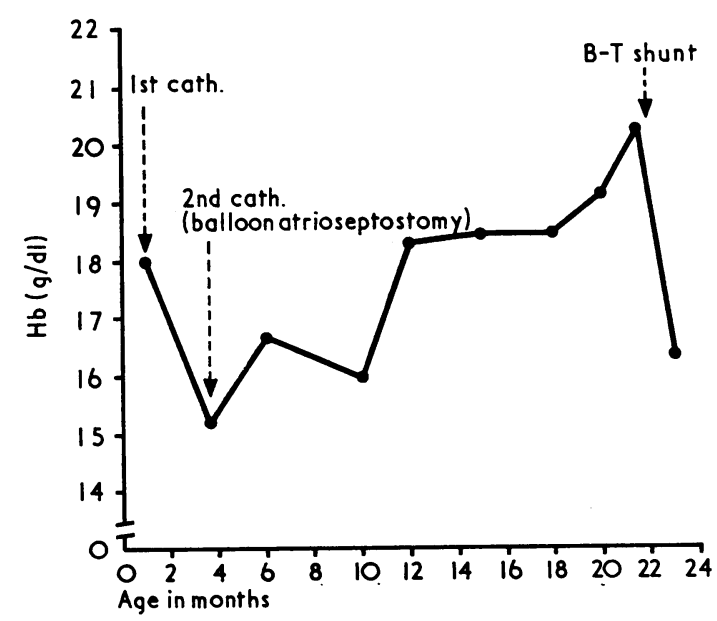

Fig. 4 Case 4. Haemoglobin ( $g / d l$ ) plotted against age in months. Note initial drop (by about 4 months) in haemoglobin to a near normal level, and gradual increase up to age of 18 months, followed by steep rise from 18 to 21 months of age (see text). The timings of the cardiac catheterisations and Blalock-Taussig (B-T) shunt are indicated. Note prompt fall in haemoglobin after shunt operation. 
The electrocardiogram showed a mean frontal plane vector of $-75^{\circ}$ and diminished anterior forces. The haemoglobin was $13.5 \mathrm{~g} / \mathrm{dl}$, and the haematocrit 42 per cent. A clinical diagnosis of tricuspid atresia was made. Because of increased cyanosis and easy fatiguability, a left Blalock-Taussig anastomosis was performed at the age of 13 months. She improved at first, but then symptoms recurred and the haematocrit increased significantly $(\mathrm{Hb} 20 \mathrm{~g} / \mathrm{dl}$ and haematocrit $60 \%$ ) at about the age of 3 years. Cardiac catheterisation and angiography confirmed the clinical diagnosis of tricuspid atresia with normally related great arteries. Left atrial angiogram in the left anterior oblique projection showed a moderate-sized ventricular septal defect (Fig. 5A). The Blalock-Taussig anastomosis was patent but small. She then had a Glenn operation, and again improved clinically, with fall in haemoglobin to
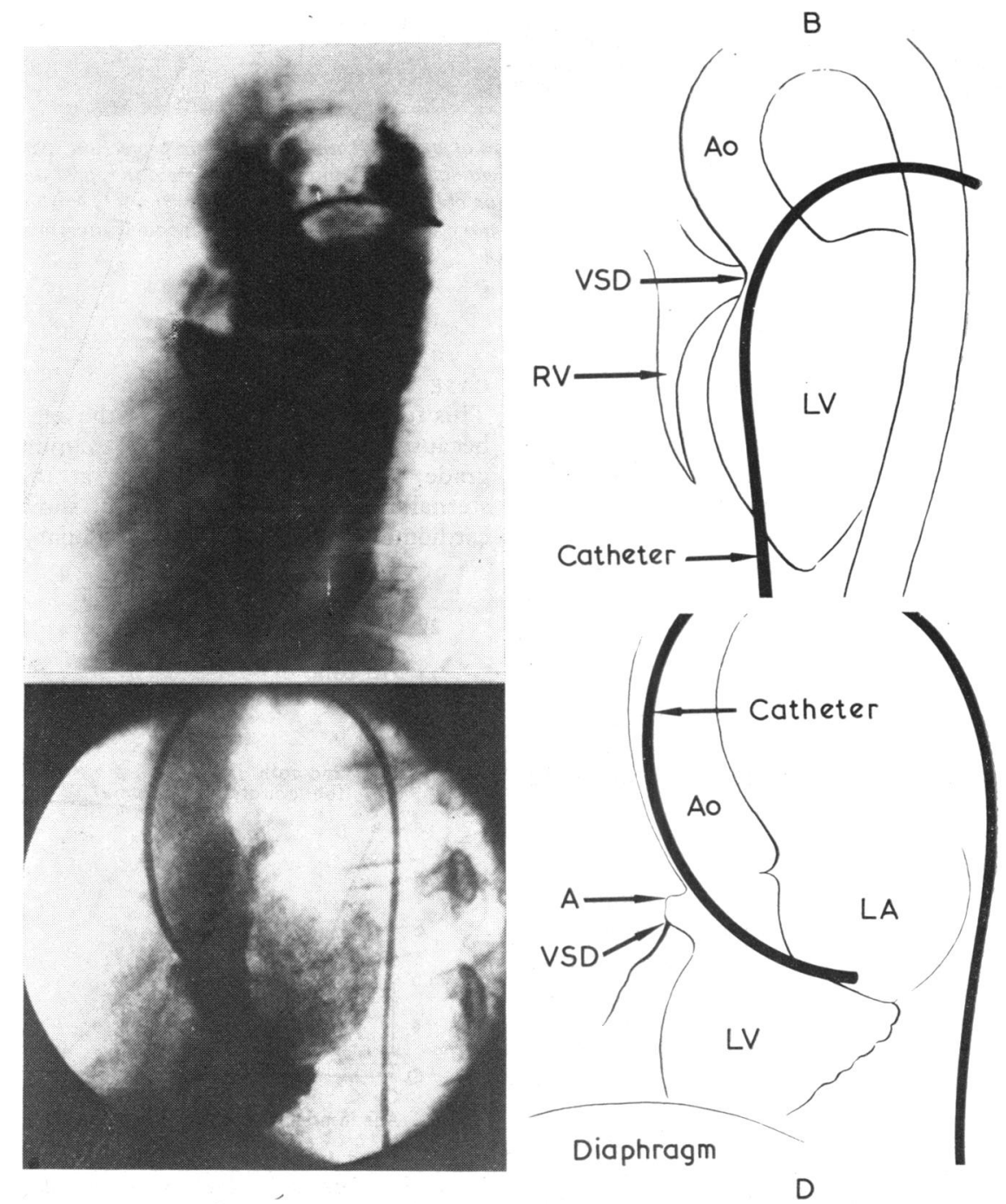

Fig. 5 Case 5. (A) and (B) Selected frame from left atrial angiogram in left anterior oblique projection at 3 years showing opacification of left ventricle $(L V)$ and aorta $(A o)$, and of right ventricle $(R V)$ through moderate sized ventricular septal defect (VSD). (C) and (D) Left ventricular angiogram in left anterior oblique projection at 16 years shows aneurysm $(A)$ of the ventricular septum with string-like jet through tiny ventricular septal defect (VSD). Minimal opacification of left atrium (related to catheter position). 
$15 \mathrm{~g} / \mathrm{dl}$. During the ensuing years she developed increasing polycythaemia and worsening symptoms. At 16 years of age moderate cyanosis and clubbing, a short grade $1 / 6$ systolic murmur at the left lower sternal border, and a grade $2 / 6$ continuous murmur below the left clavicle. The electrocardiogram was unchanged. Chest $x$-ray showed minimal cardiomegaly and normal pulmonary vascularity. Haemoglobin was $20 \mathrm{~g} / \mathrm{dl}$. A repeat cardiac catheterisation (Table 3) at this time confirmed the diagnosis of tricuspid atresia with normally related great vessels. The Glenn anastomosis was functioning well and Blalock-Taussig anastomosis showed obvious narrowing at the junction of the left subclavian and left pulmonary arteries. A selective left ventriculogram in the left anterior oblique projection showed an aneurysm of the membranous ventricular septum and a ventricular septal defect of pin-hole size at the apex of the aneurysm (Fig. 5B). At the time of Fontan operation the ventricular septal defect was $2 \mathrm{~mm}$ in size. She improved considerably after this operation.

\section{CASE 6}

This 14-year-old girl presented with severe congestive heart failure at 4 months of age. A pulmonary artery banding operation was performed and she improved clinically. At cardiac catheterisation and angiography performed elsewhere when she was 9 months old, a diagnosis of tricuspid atresia with transposition of the great arteries was made. She remained well on treatment with digitalis. When first seen by our group at 4 years, the physical findings were cyanosis and clubbing, a thrill in the suprasternal notch, a grade $3 / 6$ pansystolic murmur at the lower left sternal border, and a grade $4 / 6$ ejection systolic murmur at the upper left sternal border, and a single second heart sound. Chest $x$-ray showed cardiomegaly and increased pulmonary vascularity. The electrocardiogram showed a mean frontal plane vector of $+60^{\circ}$, and left atrial and left ventricular hypertrophy. The haematocrit was 45 per cent. Cardiac catheterisation with selective cineangiography at 5 years (Table 3) confirmed the diagnosis of tricuspid atresia with transposition of the great arteries, moderate to large ventricular septal defect with a small right ventricle (Fig. 6A), and supravalvar pulmonary artery stenosis (pulmonary artery banding). She continued well with only minimal exercise intolerance, until at 13 years of age, she developed a brain abscess which resolved with treatment. At the age of 14 years, she had moderate cyanosis and clubbing, diminished femoral pulses, a grade $3 / 6$ ejection systolic murmur with thrill at the upper right sternal border with radiation into the carotids, and a single second heart sound. Catheterisation (Table 3) and angiography confirmed the previous diagnoses; additional findings included coarctation of the aorta, normal pulmonary artery pressure beyond the surgically

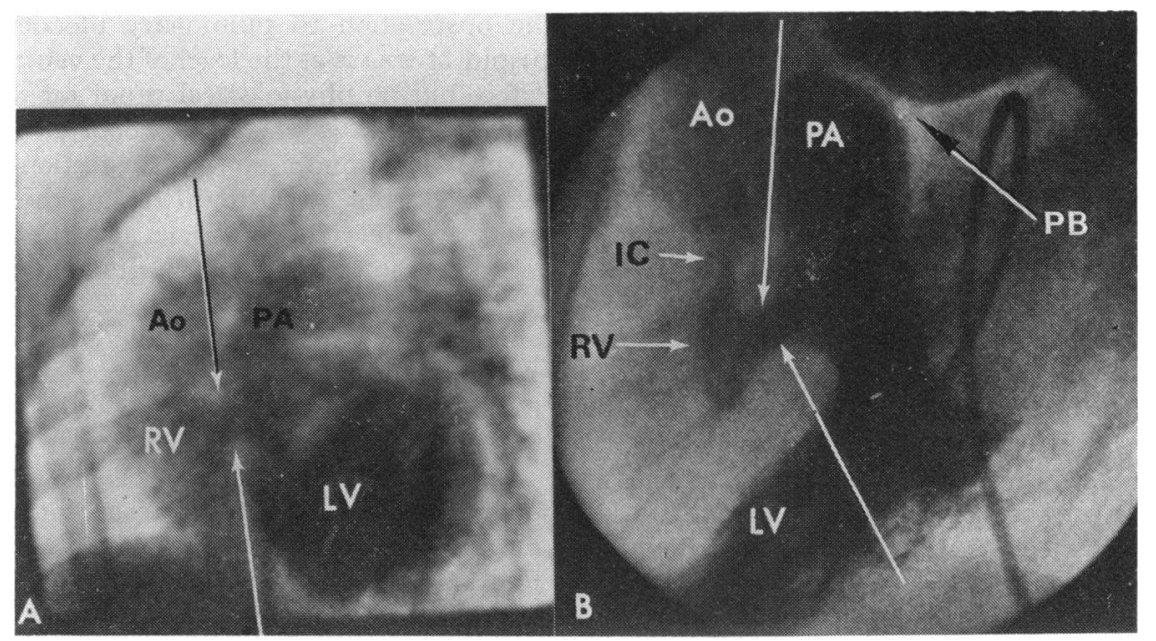

Fig. 6 Case 6. Left ventricular angiograms in left anterior oblique projection performed at 5 years $(A)$ and 14 years $(B)$. Posterior pulmonary artery $(P A)$ is opacified from left ventricle (LV). Pulmonary artery band (PB) is clearly seen in $(B)$. Right ventricle $(R V)$ and anterior aorta $(A o)$ opacify from left ventricle via ventricular septal defect (marked by the arrows). Ventricular septal defect appears to be relatively smaller in (B) than in (A); defect is smaller than aortic valve in (B). Infundibular constriction (IC) is distinctly seen in (B). 
created pulmonary band, and what appeared to be a small ventricular septal defect and narrow right ventricular outflow tract (Fig. 6B). The patient had the coarctation resected, and is now awaiting a modified Fontan operation, with bypass of ventricular septal defect and right ventricle by anastomosis of the proximal stump of the divided main pulmonary trunk to the ascending aorta (Stansel, 1975).

\section{Discussion}

Of the 6 cases described, 3 had complete and spontaneous anatomical closure of ventricular septal defects, and the findings in the other 3 cases are consistent with partial closure. For the purpose of analysis, two previously reported cases (Rao and Sissman, 1971; Rao et al., 1974) can be added to this group, which then consists of 4 cases with complete closure and 4 with partial closure. Two of the patients with complete closure (Case 1 of Rao and Sissman (1971) and Case 1 of this report) became severely hypoxic and died. In the other 2 patients (Cases 2 and 3 of this report), the decrease in pulmonary blood flow caused by closure of the ventricular septal defect may not have significant clinical effect because of the earlier systemicpulmonary shunts (Glenn anastomosis in one and Waterston shunt in the other). In 2 of the cases with partial closure of ventricular septal defect (Case 3 of Rao et al. (1974) and Case 4 of this report), the congestive heart failure improved, but in Case 4, progressive closure of the defect resulted in severe hypoxia, so that a Blalock-Taussig operation had to be performed. In the fifth case of this report, closure of the ventricular septal defect might have contributed to the decreased pulmonary blood flow but this effect was obscured by the surgical shunts. The sixth case is the only case of tricuspid atresia with transposition of the great arteries in which there seems to be some evidence for closure of the ventricular septal defect. Despite what appeared to be a small ventricular septal defect by angiography (Fig. $6 \mathrm{~B}$ ), no systolic pressure gradient was detected on withdrawal from the left ventricle to the right ventricle across the defect. Ross and Somerville (1973) reported one case of tricuspid atresia with transposition in which no pressure gradient was detected between the ventricles, but in which at necropsy the ventricular septal defect was small. The absence of pressure gradient in both these cases may be attributed to the phenomenon of 'stenosis without pressure gradient' in the presence of multiple obstructions in series (Silove et al., 1968; Rao and Linde, 1974); it has been observed that there may be no pressure gradient across a proximal obstruc- tion in the cardiovascular system (Silove et al., 1968; Rao and Linde, 1974).

Increasing cyanosis with a rise in the haematocrit was present in most cases; this was more pronounced when there was complete closure of the ventricular septal defect than when this was partial. Disappearance of a previously heard pansystolic murmur was seen in all 4 cases with complete closure and decreased heart size and/or decrease in pulmonary vascularity occurred in 6 of the 8 cases.

Complete closure of the ventricular septal defect in tricuspid atresia has previously been reported in only a few cases (Roberts et al., 1963; Meng 1969; Rao and Sissman 1971; Bargeron et al., 1972). The clinical features of the reported cases were similar to ours. Partial closure of ventricular septal defect in tricuspid atresia has also been reported previously (Gallaher and Fyler, 1967; Marcano et al., 1969; Dolara et al., 1969; Rao et al., 1974). Gallaher and Fyler (1967) reported 3 patients with tricuspid atresia who had cardiac failure and pulmonary plethora during infancy; over varying periods of time they became more cyanotic; cardiomegaly and pulmonary blood flow decreased; finally they required palliative shunt procedures to relieve symptoms of hypoxia. They suggested reduction in size of the ventricular septal defect as a possible cause of decreasing pulmonary blood flow in tricuspid atresia. Marcano et al. (1969) and Dolara et al. (1969) reported similar cases and postulated a closing ventricular septal defect as the most likely cause of diminution of pulmonary blood flow in tricuspid atresia. These observations suggested that the obstruction to pulmonary blood flow in tricuspid atresia is at the level of the ventricular septal defect but no physiological proof for this could be provided. Rao et al. (1974) reported a case (their Case 3) in support of this suggestion: a pressure record during withdrawal from the pulmonary artery to the right ventricle and then to the left ventricle showed a pressure gradient between the ventricles (MPA 28/10 $\rightarrow$ RV 28/4 $\rightarrow$ LV 80/6). This and the reports of complete and spontaneous anatomical closure of a ventricular septal defect in tricuspid atresia support the view that the obstruction is at the level of the ventricular septum.

Apart from the anatomical closure of ventricular septal defect in tricuspid atresia, intermittent and functional closure of these defects can also occur (Rao and Linde 1973; Rao et al., 1974), causing cyanotic spells in tricuspid atresia.

The incidence of closure of the ventricular septal defect in tricuspid atresia is difficult to estimate accurately because of the small number of cases reported. The 6 cases reported here were from a series of 20 cases, giving an incidence of 30 per cent. 
However, since type IA cases do not have ventricular septal defects these cases may be excluded; thus, 38 per cent ( 6 of 16) can be taken as the true incidence of spontaneous closure of ventricular septal defect in tricuspid atresia; this is similar to the incidence of spontaneous closure of isolated ventricular septal defect (Bloomfield, 1964; Hoffman and Rudolph, 1965; Hoffman and Rudolph, 1970; Keith et al., 1971). The age at which the ventricular septal defect closes appears to vary; in 4 closure was noted before 2 years of age ( 1 before 6 months and 1 before 12 months), in 3 after the age of 2 years, and in 1 between the ages of 2 and 60 months.

Several different mechanisms of closure of ventricular septal defects have been postulated. The necropsy specimens examined by the author during this and other studies (Rao and Sissman, 1971; Rao et al., 1973, 1974) and by Guller and Titus (1968) have shown that the ventricular septal defect, in most cases of tricuspid atresia is located in the muscular septum and that the defect is surrounded entirely by muscle. Therefore, progressive muscular 'encroachment' at the margins of the defect with subsequent fibrosis and covering by endocardial proliferation (Roberts et al., 1963; Meng, 1969; Rao and Sissman, 1971) seems the most probable mechanism of closure in tricuspid atresia; this view is supported by the necropsy findings in Case 1 . However, in Case 5 the ventricular septal defect appears to have closed by formation of an aneurysm of the ventricular septum as previously described (Varghese et al., 1969; Freedom et al., 1974) in isolated ventricular septal defects.

The factors initiating the closure of ventricular septal defect, if any, are not known. Because closure of the ventricular septal defect occurred in cases with or without previous systemic-pulmonary shunt operations, it is reasonable to assume that the closure of the defect in tricuspid atresia is not initiated or accelerated by surgical shunts. It appears that there is a great natural tendency for a ventricular septal defect to close spontaneously, whether it is an isolated defect or part of a more complex cardiac anomaly like tricuspid atresia, double outlet right ventricle (Edwards et al., 1952; Rao and Sissman, 1971; Rao, 1974), or transposition of the great arteries (Rao, 1972, 1974); the reason for this remains unclear.

Hitherto, only palliative surgical treatment was available, but recently Fontan and his associates (Fontan et al., 1971; Fontan and Baudet, 1971) have devised an operation for physiological correction of tricuspid atresia. Published reports (Fontan and Baudet, 1971; Ross and Somerville, 1973; Stanford et al., 1973; Kreutzer et al., 1973; Miller et al., 1974; Henry et al., 1974; Walker et al., 1975; Kreutzer, 1975) suggest that successful surgical correction of tricuspid atresia can be performed in patients older than 8 years. Patients with tricuspid atresia most commonly present with symptoms in infancy and these babies should be effectively palliated to enable them to reach the age at which surgical correction can be undertaken. The palliative procedures used are the Glenn operation and various types of systemic artery-to-pulmonary artery anastomosis. Because of the high incidence of spontaneous closure of ventricular septal defects in tricuspid atresia, the Glenn anastomosis may not be an appropriate palliative procedure. Should the ventricular septal defect close after a Glenn shunt, the left pulmonary circuit will be without blood flow. Additional reasons for avoiding a Glenn anastomosis in the symptomatic patient with tricuspid atresia are the long-term complications seen with this type of shunt procedure (Glenn, 1969; Achtel et al., 1969; Boruchow et al., 1969, 1970; Sakiyalak et al., 1971; Bargeron et al., 1972; Willman et al., 1974). Thus, a systemic artery-to-pulmonary artery shunt is preferable. Whether a Blalock-Taussig (subclavian artery-pulmonary artery) or Waterston or Potts (aortopulmonary) shunt should be performed in a given case usually depends upon the size of the pulmonary vessels. But, because central aortopulmonary shunts may result in raised pulmonary arterial pressure and resistance, and because the right atrium may not be able to maintain adequate pulmonary blood flow against this resistance after a Fontan operation (Fontan and Baudet, 1971; Kreutzer et al., 1973), central aortopulmonary shunts should be avoided. Thus, a Blalock-Taussig anastomosis is the palliative procedure of choice for tricuspid atresia. Should additional palliation be required before the patient attains the age and size suitable for a Fontan operation, a Blalock-Taussig operation on the opposite side can be performed.

The Fontan operation can also be employed for correction of tricuspid atresia with transposition (Fontan and Baudet, 1971; Ross and Somerville, 1973). This involves disconnecting the pulmonary artery from the left ventricle and anastomosing it to the right atrium via a valved conduit as well as the other steps of the Fontan operation (Fig. 7A). After this operation, the left ventricle has to pump blood into the aorta via the ventricular septal defect and the right ventricle. An adequate size of ventricular septal defect and right ventricle without obstruction is essential for a successful operation. Though the patient with type II tricuspid atresia operated on by Fontan and Baudet (1971) survived, a patient treated similarly by Ross and Somerville (1973) died 
A

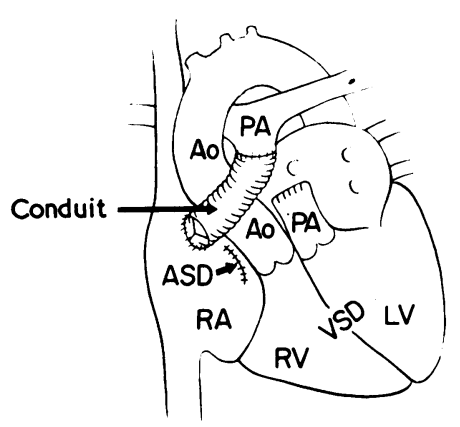

Fontan for tricuspid atresia with transposition

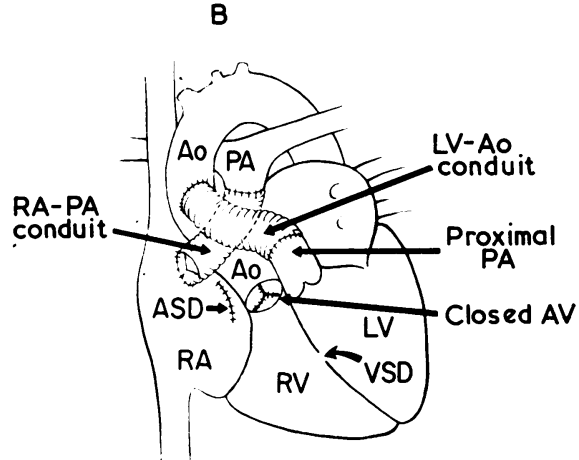

Fontan for tricuspid atresio with transposition and small VSD

Fig. 7 (A) Fontan operation for tricuspid atresia with transposition of the great arteries involves insertion of valved conduit between right atrium $(R A)$ and pulmonary artery $(P A)$ and closure of atrial septal defect $(A S D)$. Blood from left ventricle (LV) must then flow to aorta (Ao) via ventricular septal defect $(V S D)$ and right ventricle $(R V)$. (B) A small ventricular septal defect results in subaortic obstruction which is bypassed by connection of proximal stump of divided $P A$ to ascending aorta either directly or via $L V$-Ao conduit; the aortic valve ( $A V)$ is closed. The principles of this suggested operation are adopted from Stansel (1975).

of low cardiac output in the immediate postoperative period. This was attributed to subaortic obstruction caused by the small ventricular septal defect. In our case (Case 6), despite the absence of a pressure gradient across it, the ventricular septal defect appeared small angiographically. Therefore, the size of the defect should be assessed preoperatively, both by pressure measurements across it and by angiography. The size of the ventricular septal defect should also be assessed at the time of operation by inspection and/or palpation through the aortic root (Ross and Somerville, 1973). If the ventricular septal defect is found to be small it may be necessary to resect ventricular septal muscle to enlarge it, as suggested by Ross and Somerville (1973). Alternatively, the ventricular septal defect, right ventricle, and aortic valve may be bypassed by anastomosis of the proximal stump of the divided main pulmonary artery to the ascending aorta at the time of the Fontan operation (Fig. 7B), as suggested by Stansel (1975) for correction of transposition of the great arteries. If the pulmonary arterial stump is too short, a prosthetic conduit can be inserted between it and the ascending aorta.

Clinical deterioration and decreasing intensity of a previously heard systolic murmur in patients with complex congenital heart disease should lead one to suspect closure of the physiologically advantageous ventricular septal defect. A complete understanding of the circumstances surrounding the spontaneous closure of these defects and appreciation of the true nature of the changing anatomical and haemody- namic state should result in more rational and effective therapy.

The author wishes to acknowledge the contribution to this study made by the past and present paediatric cardiology and thoracic surgery staff at the Medical College of Georgia, including Drs. Robert G. Ellison, Gordon, M. Folger, Moo H. Lee, H. Victor Moore, Gordon H. Puryear, Joseph W. Rubin, Lloyd Rudy, William B. Strong, and Thomas Yeh. The author also thanks Drs. John E. Shippey, Jr., N. Raghunadha Rao, and Leland D. Stoddard for their permission to report on the necropsy specimen in Case 1, and for their assistance in preparing Fig. 2.

\section{References}

Achtel, R. A., Kaplan, S., Benzing, G., III, and Helmsworth, J. A. (1969). Superior vena cava-right pulmonary artery anastomosis: long-term results. Annals of Thoracic Surgery, $8,511$.

Arcilla, R. A., Agustasson, M. H., Bicoff, J. P., Lynfield, J., Weinberg, M., Jr., Fell, E. H., and Gasul, B. M. (1963). Further observations on the natural history of isolated ventricular septal defects in infancy and childhood: serial cardiac catheterization studies in 75 patients. Circulation, 28, 560 .

Azevedo, A. de, C., Toledo, A. N., de Carvalho, A. A., Zaniolo, W., Dohmann, H., and Roubach, R. (1958). Ventricular septal defect: an example of its relative diminution. Acta Cardiologica, 13, 513.

Bargeron, L. M., Jr., Karp, R. B., Barcia, A., Kirklin, J. W., Hunt, D., and Deverall, P. B. (1972). Late deterioration of patients after superior vena cava to right pulmonary artery anastomosis. American fournal of Cardiology, 30, 211.

Bloomfield, D. K. (1964). The natural history of ventricular 
septal defect in patients surviving infancy. Circulation, 29, 914.

Boruchow, I. B., Bartley, T. D., Elliott, L. P., and Schiebler, G. L. (1969). Late superior vena cava syndrome after superior vena cava-right-pulmonary artery anastomosis. New England fournal of Medicine, 281, 646.

Boruchow, I. B., Swenson, E. W., Elliott, L. P., Bartley, T. D., Wheat, M. W., Jr., and Schiebler, G. L. (1970). Study of the mechanisms of shunt failure after superior vena cava-right pulmonary artery anastomosis. Fournal of Thoracic and Cardiovascular Surgery, 60, 531.

Dick, M., Fyler, D. C., and Nadas, A. S. (1975). Tricuspid atresia: clinical course in 101 patients. American fournal of Cardiology, 36, 327.

Diehl, A. M., Lauer, R. M., and Shankar, K. R. (1968). Tricuspid atresia. In Heart Disease in Infants, Children and Adolescents, p. 517. Ed. by A. J. Moss and F. H. Adams. Williams and Wilkins, Baltimore.

Dolara, A., Fazzini, P. F., Marchi, F., and Tordini, B. (1969). Changing clinical features in tricuspid atresia without transposition of great vessels: report of two cases. Acta Cardiologica, 24, 275.

Edwards, J. E., and Burchell, H. B. (1949). Congenital tricuspid atresia: a classification. Medical Clinics of North America, 33, 1177.

Edwards, J. E., James, J. W., and DuShane, J. W. (1952). Congenital malformation of the heart: origin of transposed great vessels from the right ventricle associated with atresia of the left ventricular outlet, double orifice of the mitral valve, and single coronary artery. Laboratory Investigation, $1,197$.

Evans, J. R., Rowe, R. D., and Keith, J. D. (1960). Spontaneous closure of ventricular septal defects. Circulation, 22, 1044.

Fontan, F., and Baudet, E. (1971). Surgical repair of tricuspid atresia. Thorax, 26, 240.

Fontan, F., Mounicot, F. B., Baudet, E., Simonneau, J., Gordo, J., and Gouffrant, J. M. (1971). 'Correction' de l'atrésie tricuspidienne. Rapport de deux cas 'corrigés' par l'utilisation d'une technique chirugicale nouvelle. Annales de Chirurgie Thoracique et Cardio-vasculaire, 10, 39.

Freedom, R. M., White, R. D., Pieroni, D. R., Varghese, P. J., Krovetz, L. J., and Rowe, R. D. (1974). The natural history of the so-called aneurysm of the membranous ventricular septum in childhood. Circulation, 49, 375.

Gallaher, M. E., and Fyler, D. C. (1967). Observations on changing hemodynamics in tricuspid atresia without associated transposition of the great vessels. Circulation, 35, 381 .

Gasul, B. M., Arcilla, R. A., and Lev, M. (1966). Heart Disease in Children, p. 656. Lippincott, Philadelphia.

Glenn, W. W. L. (1969). Superior-vena-cava-rightpulmonary-artery anastomosis (letter). New England fournal of Medicine, 281, 1424.

Guller, B., and Titus, J. L. (1968). Morphological studies in tricuspid atresia. Circulation, 38, 977.

Henry, J. N., Devloo, R. A. E., Ritter, D. G., Mair, D. D., Davis, G. D., and Danielson, C. K. (1974). Tricuspid atresia: successful surgical 'correction' in two patients using porcine xenograft valves. Mayo Clinic Proceedings, 49, 803.

Hoffman, J. I. E., and Rudolph, A. M. (1965). The natural history of ventricular septal defects in infancy. American fournal of Cardiology, 16, 634.

Hoffman, J. I. E., and Rudolph, A. M. (1970). The natural history of isolated ventricular septal defect with special reference to selection of patients for surgery. Advances in Pediatrics, 17, 57.

Keith, J. D., Collins, G. F. N., Rose, V., Calder, L., and Kidd, B. S. L. (1971). Improved prognosis in ventricular septal defect. In The Natural History and Progress in Treatment of Congenital Heart Defects, p. 5. Ed. by B. S. L. Kidd and J. D. Keith. C. C. Thomas, Springfield, Illinois.

Keith, J. D., Rowe, R. D., and Vlad, P. (1967). Heart Disease in Infancy and Childhood, 2nd ed., p. 644. Macmillan, New York.

Kreutzer, G. (1975). Tricuspid atresia-recent surgical approaches. Paper presented at the International Symposium on the Child with Congenital Heart Disease after Surgery, Toronto, Canada.

Kreutzer, G., Galindez, E., Bono, H., de Palma, C., and Laure, J. P. (1973). An operation for the correction of tricuspid atresia. Fournal of Thoracic and Cardiovascular Surgery, 66, 613.

Marcano, B. A., Riemenschneider, T. A., Ruttenberg, H. D., Goldberg, S. J., and Gyepes, M. (1969). Tricuspid atresia with increased pulmonary blood flow: an analysis of 13 cases. Circulation, 40, 399.

Meng, C. C. L. (1969). Spontaneous closure of ventricular septal defect in tricuspid atresia. Fournal of Pediatrics, $75,697$.

Miller, R. A., Pahaljani, D., Serratto, M., and Tatooles, C. (1974). Clinical studies after Fontan's operation for tricuspid atresia (abstract). American fournal of Cardiology, 33, 157.

Nadas, A. S., and Fyler, D. C. (1972). Pediatric Cardiology, 3rd ed. Saunders, Philadelphia.

Nadas, A. S., Scott, L. P., Hauck, A. J., and Rudolph, A. M. (1961). Spontaneous functional closure of ventricular septal defects. New England fournal of Medicine, 264, 309.

Neill, C. A., and Brink, A. J. (1955). Left axis deviation in tricuspid atresia and single ventricle: the electrocardiogram in 36 autopsied cases. Circulation, 12, 612.

Rao, P. S. (1972). Left ventricular obstruction in double outlet right ventricle (letter). American Heart fournal, 83, 289.

Rao, P. S. (1974). Physiologically advantageous ventricular septal defects and their spontaneous closure. In Proceedings of the XIV International Congress of Pediatrics, October, 1974, Buenos Aires, Argentina, Vol. VII, CardiologyNephrology, p. 65.

Rao, P. S., Jue, K. L., Isabel-Jones, J., and Ruttenberg, H. D. (1973). Ebstein's malformation of the tricuspid valve with atresia: differentiation from isolated tricuspid atresia. American fournal of Cardiology, 32, 1004.

Rao, P. S., and Linde, L. M. (1973). Functional closure of ventricular septal defects in tricuspid atresia (abstract). Pediatric Research, 7, 304.

Rao, P. S., and Linde, L. M. (1974). Pressure and energy in the cardiovascular chambers. Chest, 66, 176.

Rao, P. S., Linde, L. M., Liebman, J., and Perrin, E. (1974). Functional closure of physiologically advantageous ventricular septal defects: observations in three cases with tricuspid atresia. American fournal of Diseases of Children, 127, 36.

Rao, P. S., and Sissman, N. J. (1971). Spontaneous closure of physiologically advantageous ventricular septal defects. Circulation, 43, 83.

Roberts, W. C., Morrow, A. G., Mason, D. T., and Braunwald, E. (1963). Spontaneous closure of ventricular septal defect: anatomic proof in an adult with tricuspid atresia. Circulation, 27, 90.

Ross, D. N., and Somerville, J. (1973). Surgical correction of tricuspid atresia. Lancet, 1, 845.

Sakiyalak, P., Ankeney, J. L., Liebman, J., and DeMeules, J. (1971). Results of superior vena cava-to-pulmonary artery shunt in the treatment of cyanotic heart disease. Annals of Thoracic Surgery, 12, 514.

Silove, E. D., Vogel, J. H. K., and Grover, R. F. (1968). The pressure gradient in ventricular outflow obstruction: 
influence of peripheral resistance. Cardiovascular Research, $2,234$.

Stanford, W., Armstrong, R. G., Cline, R. E., and King, T. D. (1973). Right atrium-pulmonary artery allograft for correction of tricuspid atresia. Fournal of Thoracic and Cardiovascular Surgery, 66, 105.

Stansel, H. C., Jr. (1975). A new operation for d-loop transposition of the great vessels. Annals of Thoracic Surgery, $19,565$.

Taussig, H. B., Keinonen, R., Momberger, N., and Kirk, H. (1973). Long-time observations on the Blalock-Taussig operation. IV: Tricuspid atresia. fohns Hopkins Medical fournal, $132,135$.

Varghese, P. J., Izukawa, T., Celermajer, J., Simon, A., and Rowe, R. D. (1969). Aneurysm of the membranous ven- tricular septum: a method of spontaneous closure of small ventricular septal defect. American fournal of Cardiology, 24, 531.

Walker, D. R., Sbokos, C. G., and Lennox, S. C. (1975). Correction of tricuspid atresia. British Heart fournal, 37, 282.

Willman, V. L., Barner, H. B., Mudd, J. G., Fagan, L. F., and Kaiser, G. C. (1974). Superior vena cava-pulmonary artery anastomosis. fournal of Thoracic and Cardiovascular Surgery, 67, 380.

Requests for reprints to Dr. P. Syamasundar Rao, Department of Pediatrics, Medical College of Georgia, Augusta, Georgia 30902, U.S.A. 